\title{
Blended learning in higher education: Three different design approaches
}

\author{
Ali Alammary, Judy Sheard, Angela Carbone \\ Monash University, Australia
}

\begin{abstract}
Blended learning has been growing in popularity as it has proved to be an effective approach for accommodating an increasingly diverse student population whilst adding value to the learning environment through incorporation of online teaching resources. Despite this growing interest, there is ongoing debate about the definition of the concept of blended learning. As a result, teachers in higher education have developed different understandings of the term and different design approaches have evolved. Selecting the most appropriate design approach for a blended course is a major challenge for many teachers in higher education institutions who are new to the idea of blended learning. This paper aims to provide guidance to help teachers of traditional face-to-face courses in selecting the most appropriate approach to use when designing their blended courses. Firstly, it discusses the different definitions of the term blended learning and how they have resulted in a number of design approaches. It then classifies these approaches into: lowimpact, medium-impact and high-impact blends according to the potential changes to the existing teaching program and student learning experience. Finally, it describes the benefits and the challenges of applying each approach and provides recommendations about when and how each approach should be used.
\end{abstract}

\section{Introduction}

Over the last decade, blended learning has been growing in demand and popularity in higher education and has become a widespread teaching phenomenon. It becomes increasingly evident that blended learning can overcome various limitations related to online learning and face-to-face instruction. A metaanalysis of more than 1,100 empirical studies published between 1996 and 2008 concluded that blended learning proves to be more effective than either online learning or face-to-face instruction (Means, Toyama, Murphy, Bakia, \& Jones, 2009). For many researchers, it is almost certain that blended learning will be the new traditional model for course delivery in higher education (Norberg, Dziuban, \& Moskal, 2011; Ross \& Gage, 2006). The question now is not whether to blend or not; it is how to design an effective blend.

The literature shows that blended learning courses are designed in many different ways, ranging from adding extra online activities to a traditional face-to-face course, to building the whole blended learning course from scratch. The lack of a single accepted definition for the term blended learning (Deperlioglu \& Kose, 2013; Graham, 2012b; Lee, Fong, \& Gordon, 2013; Stacey \& Gerbic, 2008) causes teachers to understand blended learning in different ways and then design their courses according to their own understanding of the concept. With a large number of blended learning designs, selecting the most appropriate design approach is becoming a major challenge, especially for teachers who lack the necessary theoretical preparation and experimental experience with blended learning, which is the case of the majority of teachers in higher education (Huang \& Zhou, 2005).

Although extensive academic research has proposed and discussed a number of blended learning design approaches (Boyle, Bradley, Chalk, Jones, \& Pickard, 2003; Garrison \& Vaughan, 2011; Hoic-Bozic, Mornar, \& Boticki, 2009; Huang \& Zhou, 2005; McCarthy, 2010; Newcombe, 2011), much less research has tried to classify these design approaches and compare them to identify the benefits and challenges of applying each (Graham, 2009, 2012a; Twigg, 2003).

To enhance the understanding of blended learning course design and contribute towards the developing of the existing literature in this area, the current study aims to synthesize the current literature on the design of blended learning courses. It will then propose a number of recommendations that can help teachers of traditional face-to-face courses in selecting the most appropriate approach to design their blended learning courses. The research questions driving this study are as follows: 
(1) What are the different blended learning design approaches and what are the benefits and challenges of applying each one of them?

(2) What are the factors that teachers in higher education should consider when selecting the most appropriate design approach?

(3) When should each design approach be applied? And how should it be applied?

The remainder of the paper is structured as follows: First, the variety of definitions of the term blended learning are discussed and an explaination of how these different definitions have led to a number of design approaches is given. The different design approaches are classified and explained and the benefits and challenges of each are proposed. Finally, the factors that teachers should consider when selecting the most appropriate design approach and recommendations about when and how each approach should be used are presented.

\section{Review method}

To gather relevant articles for our literature review, we searched a number of large databases that contain publications on e-learning and blended learning such as ACM digital library, ProQuest, Computer database, ScienceDirect, IEEE Xplore and Google Scholar.

The search terms used included: "design" + "hybrid course", "design" + "blended course", "approach" + "blended learning", "approach" + "hybrid course", "blended learning" + "model" and "hybrid course"+ "model".

The decision to include or exclude an article was based on the information provided in the title, abstract and conclusion in addition to the publication date. A first selection was made by the date the article was published. Priority was given to articles published over the last 10 years, which is the period of time when blended learning has been rapidly adopted in higher education institutions. A second criterion was the context of the article. Only studies conducted in the context of higher education were included. The last selection criterion was the country where the study was conducted. The aim was to look at different experiences from different parts of the world.

At last, all selected articles were analyzed with respect to the following analysis questions:

1. Does the article describe a new design approach or one that has been already identified?

2. How is the concept of blended learning understood and how does this understanding affect the course design?

3. What was the type of evaluation that was carried out to evaluate the success of the approach?

4. Is there any justification for why that particular design approach was applied?

\section{The concept of blended learning}

Blended learning is not a new term; it has been in use for the last two decades and a number of meanings of the term have evolved. According to Graham (2012b), blended learning is defined with "considerable variation across institutional contexts" (p. 17). Within this brief background section, some of the most widely used definitions of the term will be discussed.

In 2002, Driscoll identified four different 'concepts' denoted by blended learning (p. 1):

1.To combine or mix modes of web-based technology (e.g., live virtual classroom, self-paced instruction, collaborative learning, streaming video, audio, and text) to accomplish an educational goal.

2.To combine various pedagogical approaches (e.g., constructivism, behaviorism, cognitivism) to produce an optimal learning outcome with or without instructional technology.

3.To combine any form of instructional technology (e.g., videotape, CD-ROM, web-based training, film) with face-to-face instructor-led training.

4.To mix or combine instructional technology with actual job tasks in order to create a harmonious effect of learning and working. 
The last definition is only appropriate in the corporate world while the other three are also appropriate in the higher education context.

Drawing on the Driscoll (2002) work, Oliver and Trigwell (2005) proposed three different definitions of blended learning (p. 17):

(1) "The combination of media and tools employed in an e-learning environment".

(2) "The combination of a number of pedagogic approaches, irrespective of the learning technology used".

(3) "The integrated combination of traditional learning with web-based online approaches".

Despite the widespread usage of Oliver and Trigwell's (2005) first and the second definitions, they have two obvious problems. First, they can also be used to describe other types of courses. According to Sharma (2010), the first one can describe a purely distance learning course, while the second one can describe a traditional face-to-face course that combines different pedagogical approaches. Second, neither get at the essence of the term blended learning and how it has emerged (Graham, 2012a).

The third definition has been regarded as the most common and the most classic, reflecting the historical emergence of blended learning (Graham, 2012a; Oliver \& Trigwell, 2005; Sharma, 2010); however, this definition is also regarded as a broad and perhaps deficient definition of blended learning (Bliuc, Goodyear, \& Ellis, 2007; Clark, 2003; Picciano, 2009). According to Clark (2003), it is dangerous to look at blended learning as a simple method of combining classroom teaching and online learning. He also added that this simple 'pick-and-mix' definition of the concept is insufficient. It causes many teachers, who do not want to spend much time on e-learning and who want to preserve what they have, to change very little in their courses and call them blended learning. The most common practice to design blended learning courses, documented by many researchers (Brunner, 2006; Kaleta, Skibba, \& Joosten, 2007), is to simply add extra online activities to an existing traditional course. The result is a combination of traditional learning and online approaches, which is considered blended learning according to the third definition.

In a 2005 workshop on blended learning funded by the Alfred P. Sloan Foundation, the participants came up with a narrower definition of the term. They described blended learning courses as:

Courses that integrate online with traditional face-to-face class activities in a planned, pedagogically valuable manner; and where a portion (institutionally defined) of face-to-face time is replaced by online activity. (Picciano, 2009, p. 8)

The most obvious concern with this definition is that it considers only one approach to the process of designing blended learning courses, replacing activities in an existing face-to-face course. As will be discussed in this paper, there are other approaches to the design of blended learning courses, and each one has its benefits and challenges.

In another attempt to provide a more focused definition of the term, Bliuc et al. (2007) gave the following definition:

Blended learning describes learning activities that involve a systematic combination of copresent (face-to-face) interactions and technologically mediated interactions between students, teachers and learning resources. (p. 234)

A similar definition is offered by Garrison and Kanuka (2004), where they defined blended learning as:

The thoughtful integration of classroom face-to-face learning experiences with on-line experiences. (p. 96)

Stating that the combination should be systematic or the integration should be thoughtful, gives a strong implication that the process of designing blended courses needs to involve a great deal of planning and forethought. 
Describing blended learning as a mix of online and face-to-face learning activities (Bliuc et al., 2007; Garrison \& Kanuka, 2004; Graham, 2012a) has been also regarded as a narrow definition. Verkroost, Meijerink, Lintsen, and Veen (2008) explained that such a definition is narrow in the sense that blended learning is conceptualised as making a selection between new and old media as if they can replace each other. They added that the main problem with this definition is that it does not address the idea that the whole process of learning needs to be redesigned. They defined blended learning in a broad way as:

The total mix of pedagogical methods, using a combination of different learning strategies, both with and without the use of technology. (p. 501)

The main concern here is that this definition can be also used to describe a totally face-to-face course or a purely distance learning course. It also implies nothing about the process of mixing up the blended course's components. Thoughtless addition of a different pedagogical method to a traditional course would make it a blended course according to this definition.

From the literature review, it is evident that the term blended learning has been defined either in a broad way where it encompasses a broad range of learning modes, or in a very specific way that might limit the great potentials of the concept. All definitions, however, have one essential component in common - an integration of different instructional methods. The instructional methods that are combined are those that belong to the two historical models of instruction: traditional face-to-face learning and computermediated learning. For the purpose of this paper, blended learning courses are courses that:

(1) thoughtfully integrate different instructional methods such as: lecture, discussion group, selfpaced activity; and

(2) contain both face-to-face and computer-mediated portions.

This definition encapsulates the two key ideas of blended learning - a process that is pedagogically based and a product (course) with a mixture of face-to-face and online components.

\section{Different design approaches}

As discussed in the previous section, there is ongoing debate about the best definition of blended learning. The term means different things to different people; however, many researchers suggest that the lack of a universally accepted definition may in fact be part of the term's strength. According to Driscoll (2002), the ambiguity of the term might appear to be an academic point; however, this array of definitions shows the untapped potential of blended learning. According to Sharpe, Benfield, Roberts, and Francis (2006), the lack of clarity around blended learning makes it possible for teachers and course designers to develop their own meaning of the term within the context of their courses or institutions.

An instructor's understanding of the term blended learning is normally used as a basis for course design. According to Westbrook (2008), defining blended learning is of great importance as it influences the process of designing blended learning courses. Looking at blended learning as a simple method of combining traditional learning with web-based online approaches has caused many teachers to add extra online activities to their traditional face-to-face courses and call this blended learning (Brunner, 2006; Kaleta et al., 2007). Adapting the more narrow definition given by the Alfred P. Sloan Foundation workshop participants in 2005, where they stated that a portion of traditional course time needs to be replaced by an online activity, would force teachers to design their courses in a very particular way. Other definitions, that talk about "harmonious balance" (Osguthorpe \& Graham, 2003, p. 229) or "thoughtful integration" (Garrison \& Kanuka, 2004, p. 96) of face-to-face and online components, imply that the process of designing blended courses needs to involve a great deal of planning and forethought.

By examining different processes of designing blended learning courses, we were able to identify three distinct design approaches:

(1) Low-impact blend: adding extra activities to an existing course

(2) Medium-impact blend: replacing activities in an existing course

(3) High-impact blend: building the blended course from scratch. 
Classifying these approaches as low-impact, medium-impact and high-impact blends has been made according to the potential changes to the existing teaching program and student learning experience.

\section{Low-impact blend: adding extra activities}

In the low-impact approach, extra online activities are added to a traditional face-to-face course. A study conducted by Kaleta et al. (2007) found that most teachers designing blended courses add online components to their traditional courses without eliminating any of the existing activities. They called this phenomenon "the course-and-a-half syndrome" (p. 127). Kaleta et al. proposed that adding extra online activities onto an already established course normally happens when inexperienced teachers build their first blended learning course. By simply adding on to their courses, these teachers attempt to get the benefits of blended learning without investing the effort in rethinking the whole course objectives within the context of a blended learning model.

In other cases, however, the added activity is a result of a pedagogical need and proves to be a valuable addition to the traditional course. An example is the work of McCarthy (2010), who added an online activity to a course called Imaging Our World to encourage students to interact more with their peers. In addition to the traditional teaching modes of lectures and tutorials, McCarthy required his students to submit some work online to Facebook and to provide critiques of their peers' submissions. Resulting discussions were then transferred into the physical classroom to build meaningful relationships between students based on the embryonic online connections. McCarthy's aim of adding the online activity was to strengthen the face-to-face engagements between students. He evaluated his work using weekly feedback from students, pre- and post-semester questionnaires and project-specific reflections at the end of the semester. He discovered that the additional activity hosted by Facebook created a platform for students to establish preliminary academic and social interactions with their peers, while meeting the diverse learning needs.

In considering the low-impact approach, we identified four benefits and five challenges.

\section{Benefits}

(1) An easy approach for designing blended learning courses, potentially encouraging hesitant teachers to try blended learning. According to Silverwood (2006), teachers who could benefit from blended learning may be reluctant to try it because they think that blended learning is very complex and highly technical.

(2) A quick approach to producing a blended learning course. Driven by a specific pedagogical need, teachers can directly add a new activity that appropriately meets that need without consuming extra time and effort in rethinking and replanning the whole course or investigating the many possible blended learning components and delivery methods. An example is McCarthy's (2010) Facebook activity.

(3) A low risk of failure when applied carefully. According to Vaughan (2007), the three major risk factors identified by teachers who have taught blended courses are: fear of receiving lower student evaluations, fear of losing control over the course, and uncertainty about the impact of online learning on classroom relationships. Adding an activity while keeping the traditional course almost the same can minimize these risks.

(4) Minimal experience in teaching the traditional course is enough to design the blended course. With limited experience the instructor can spot the part of the course that could be enhanced by an extra online activity.

\section{Challenges}

(1) Teachers need to have some technological knowledge to successfully apply this approach. According to Cennamo, Ross, and Ertmer (2009), to successfully integrate technology into the teaching experience, teachers need knowledge that can allow them to:

- identify which technological tool is needed to meet a specific pedagogical goal

- $\quad$ specify how the tool will be used to help student to achieve that goal

- enhance students' ability to use appropriate technological tools in the different phases of the learning process: exploration, analysis and production 
- $\quad$ select and adopt technological tools that can allow them to identify need and resolve issues related to their own professional development.

(2) A low-impact blend has a high risk of producing two separate courses. According to Newcombe (2011), adding online work to a traditional course without reducing in-class time often leads to two separate courses, one online and one face-to-face.

(3) Adding an extra activity can be seen by students as a burden rather than a bonus. The added activity can be regarded by many students as just another task on top of an already content-heavy course (Garrison \& Vaughan, 2011).

(4) Adding a new activity without eliminating an existing one can excessively increase the instructor's workload. Teachers can face time constraints and overwhelming workloads as a result of adding additional online teaching resources (Reeves, 2003).

(5) Extra activity in an existing course is often not recognized by administrators, and teachers are therefore not compensated for their efforts (Amiel \& Orey, 2007). According to Lee and Lee (2008), inadequate compensation and incentives is one of the main factors negatively affecting teachers' e-learning use.

\section{Recommendations}

(1) An instructor should start by adding a simple online activity that they and their students can easily manage, for example an online discussion board (Hofmann, 2006) or the Facebook activity that McCarthy (2010) added to his course. Later, if more online activities are needed, a mediumimpact approach involving replacement could be considered.

(2) The addition of an activity must be driven by a specific pedagogical need, rather than, say, technology for technology's sake. Teachers therefore need to find out what is problematic or lacking in their courses and understand how to apply the technologies and teaching approaches to address these issues (Picciano, 2009).

(3) The added activity should be well integrated into the course. It is essential to consider the connection between what occurs in class and what happens online (Chen \& Looi, 2007; Kaleta et al., 2007).

(4) The course should not be overloaded with tasks and activities. It is worthwhile investigating students' opinions about the course components. Sharpe et al. (2006) reported that consistent and transparent communication with students about their opinions and expectations is essential for the success of the blended learning experience.

(5) A low-impact blend is recommended for teachers with no experience in designing for blended learning. It is easy to implement and has a low risk of failure.

\section{Medium-impact blend: replacing activities}

In the medium-impact approach, an existing course is redesigned by replacing some of the face-to-face activities by online components. The assumption behind this approach is that some parts of the course would be more effective as online activities. In some cases, the remaining face-to-face sessions are kept exactly the same, while in other cases, some changes are made to the inclass activities (Twigg, 2003). An example of this approach is the redesign of a second-year political science course (Garrison \& Vaughan, 2011). The course was originally delivered via three one-hour lectures per week. The instructor noticed that the case studies discussed in class were dominated by the same four or five students. The replacement approach was applied, and the three lectures were reduced to two and an online discussion was introduced. Using a learning management system (LMS) for the online discussion, the professor divided students into small groups and monitored the discussion time. The LMS was also used to provide students with information about the nature, frequency and length of their contributions. The professor increased the credit for the discussion to $10 \%$ of the final mark. The redesign produced promising results, involving the students in more sustained and meaningful discourse.

In considering the medium-impact approach, we identified four benefits and five challenges.

Benefits

(1) This approach allows teachers to start simply and implement incrementally, replacing course components as required (Duhaney, 2004).

(2) The experience gained in using this approach can help build teachers' confidence in running a blended learning course (Ertmer \& Ottenbreit-Leftwich, 2010). 
(3) A useful approach for teachers with some experience in designing for blended learning who do not want to risk making significant change to their courses. Kaleta, Garnham, and Aycock (2005) noted that teachers normally prefer to teach in the same traditional way that they are familiar and comfortable with and find it hard and challenging to commit a significant amount of time and effort to develop a new course.

(4) Allows teachers ongoing opportunities to experiment with different approaches to learning and more types of educational technologies without losing the whole benefits of the traditional course. According to Aycock, Garnham, and Kaleta (2002), learning to employ technology in an appropriate and effective way is challenging and can improve with experience.

\section{Challenges}

(1) Teachers need to have good technological knowledge and some confidence to apply this approach, as there is no going back to the previous method of teaching. Ertmer and Ottenbreit-Leftwich (2010) pointed out that knowledge of technology is essential to facilitate students' learning although it is not sufficient if the teacher does not feel confident using that knowledge.

(2) The replacement and integration of new course components requires dedicated time and effort to produce the blended course.

(3) There are no defined standards to guide decisions as to how much or what part of courses can be replaced. Such decisions are influenced by many factors, mainly the nature of the course content and the intentions of the instructor (Vaughan, 2007).

(4) Prior experience in teaching the traditional course is useful. A key challenge when designing a blended learning course using this approach is to identify the parts of the course that do not work properly in the traditional format and then decide if it can work better online. Having little or no prior experience in teaching the course makes this process difficult.

(5) Intensive long-term planning, observation and evaluation of the course are necessary for a successful implementation. Arriving at a good balance between online and face-to-face components is a result of a gradual process of introducing new resources or techniques to replace the existing components and then evaluating whether the use of these new resources or techniques is helping students in achieving the learning targets (Duhaney, 2004).

\section{Recommendations}

(1) Teachers should apply the replacement approach incrementally. They should start by moving a small chunk of their syllabus to online, reducing face-to-face class time accordingly and then scale as necessary until they arrive at a harmonious balance between face-to-face and online (Brunner, 2006; Duhaney, 2004).

(2) The harmonious balance will vary from course to course. Variations exist due to a number of factors, including student characteristics, instructor experience, teaching style, course instructional goals and available online resources. In some courses more face-to-face than online will be appropriate, whilst others will tip the balance in favour of online components. Still other courses will mix the two models of instruction somewhat equally (Dönmez \& Aşkar, 2005; Dziuban, Moskal, \& Hartman, 2005).

(3) Reaching a harmonious balance will require continuous review and regular course evaluation. According to Sharpe et al. (2006), iterative course redesign should consider evaluative feedback as a critical success factor for course improvement. Teachers' accumulated experience in designing for blended learning can play a vital role in reaching this balance. According to Ocak (2011), striking a good balance between face-to-face and online components is complicated and requires expertise.

(4) This approach is achievable by teachers with medium- to long-term prior experience in teaching the traditional course. Many critical decisions are going to be made throughout the replacement process such as how much or what part of courses can be replaced (Vaughan, 2007). The teacher's experience is essential in making the right decisions.

(5) Intuitional support is important for the success of this approach. Vaughan (2007), when discussing this approach, pointed out that providing technical support, considering teachers' workload and dealing with their fears and resistance to blended learning are important for the success of the blended learning experience. He also emphasized the need for professional development to help teachers in learning new teaching and technology skills and to assist them to decide the most appropriate delivery methods to achieve their course objectives. Educational designers, according 
to Torrisi-Steele and Davis (2000), can also play an important role in providing advice about the range of available technologies and the advantages and disadvantages of using each one of them.

\section{High-impact blend: building from scratch}

In the high-impact approach the blended learning course is built from scratch. This approach has been described in the literature in various ways such as full redesign, total redesign, radical change. A common way to apply this approach has been described by Harriman (2004) and Hofmann (2006). They recommended that instead of looking at an entire course, the instructor needs to look at each single course learning outcome. For each outcome, the instructor needs to determine the best delivery option of that outcome. They proposed that by applying this approach at the learning outcomes level, teachers can get the most effective blend of technologies and can produce a better curriculum. This approach is consistent with the common model of curriculum development, called constructive alignment, in which assessment tasks are aligned with the learning outcomes (Biggs, 1996). Hofmann also added that it is wrong to assume that redesigning an existing course will take less time than building a new course and that designers should build the whole course from scratch without being worried about "slaying the sacred cows of successful traditional programs" (Hofmann, 2006, p. 33).

In considering the high impact approach, we identified three benefits and five challenges.

Benefits

(1) Provides an opportunity to make enhancements to and reduce or eliminate problems that the current course might have. Teachers start from a fresh perspective with a better chance to come up with more successful course, especially when the traditional one has some problems (Graham, 2012a).

(2) Allows better integration of online and face-to-face components. According to Littlejohn and Pegler (2007), it is essential to build the course from scratch to create effective integration of faceto-face and online components.

(3) Allows teachers the opportunity to get the maximum benefits of blended learning and to better meet their students' needs. Building the course from scratch provides a better chance to rethink and redesign the whole course with learners' needs in mind. Teachers are able to consider a wider choice of delivery mediums to integrate into their courses and that will increase the effectiveness of the courses (Carman, 2002).

\section{Challenges}

(1) A high level of technological knowledge and confidence are necessary to successfully apply this approach. With a high level of technological competency, teachers can readily learn new technology tools and use them in their courses (Cook, Owston, \& Garrison, 2004). Wozney, Venkatesh, and Abrami (2006) found that one of the greatest factors that influence teachers' technology integration was their confidence that this technology could help them to better achieve instructional goals.

(2) The approach has a higher risk of failure than the other approaches because it may result in a totally new and untried course being introduced to students.

(3) Teachers must consider a large number of possible blended learning components and fully understand the implications of these. According to Walters (2008), the large choice of delivery mediums, wide variety of technology combinations and the lack of exemplars to follow for particular mixes means that teachers face complex situations and therefore pressure when redesigning their courses.

(4) Requires experience in designing for blended learning. According to Huang and Zhou (2005), teachers who lack the necessary theoretical knowledge and experimental experience will find it hard to take full advantage of blended learning. Ellis, Steed, and Applebee (2006) also stated that familiarity with technology and incremental experimentation with blended learning can help teachers to understand how technological media are related to teaching.

(5) Planning and developing a new blended learning course takes a long time to apply. Vaughan (2007) proposed that developing a blended course normally takes two to three times longer than developing a similar course in the traditional format. 


\section{Recommendations}

(1) Teachers with no or limited experience in designing for blended learning should try one of the two other approaches first to gain some experience that can help them in applying this approach. Designing an effective blended learning course requires a great deal of knowledge and expertise to help selecting the learning activities that are better taught in the classroom and others that need to be created for online (Walters, 2008). Mortera-Gutierrez (2006) reported that one of the worst practices when teaching a blended course is that teachers do not use the most appropriate mediums to deliver the instruction.

(2) Teachers should be prepared to invest considerable time in the design. According to Ragan (2007), full course design for blended learning courses is time consuming, and teachers should allow at least six months' lead time for course development; however, one year is preferred. Partridge, Ponting, and McCay (2011) found that the greatest barrier to implement a successful blended learning experience is a lack of time.

(3) Teachers should consider including a variety of delivery medium in their blend. According to Carman (2002), e-learning is most effective when it uses a blend of different delivery options.

(4) Institutional support is a key factor for the success of this approach. According to Aycock et al. (2002), full course design is needed to obtain an effective blended learning experience, and, to ensure this, there must be a high-level of institutional support in the form of time release, professional development, funding and technical support. Considering the large number of online components that need to be considered, teachers should undergo professional development that focuses on the proper use of new educational technologies that teachers have not experienced before. The role of educational designers is also very important, not only to provide advice during the development stage, but also to review the new course (Moskal, Dziuban, \& Hartman, 2013).

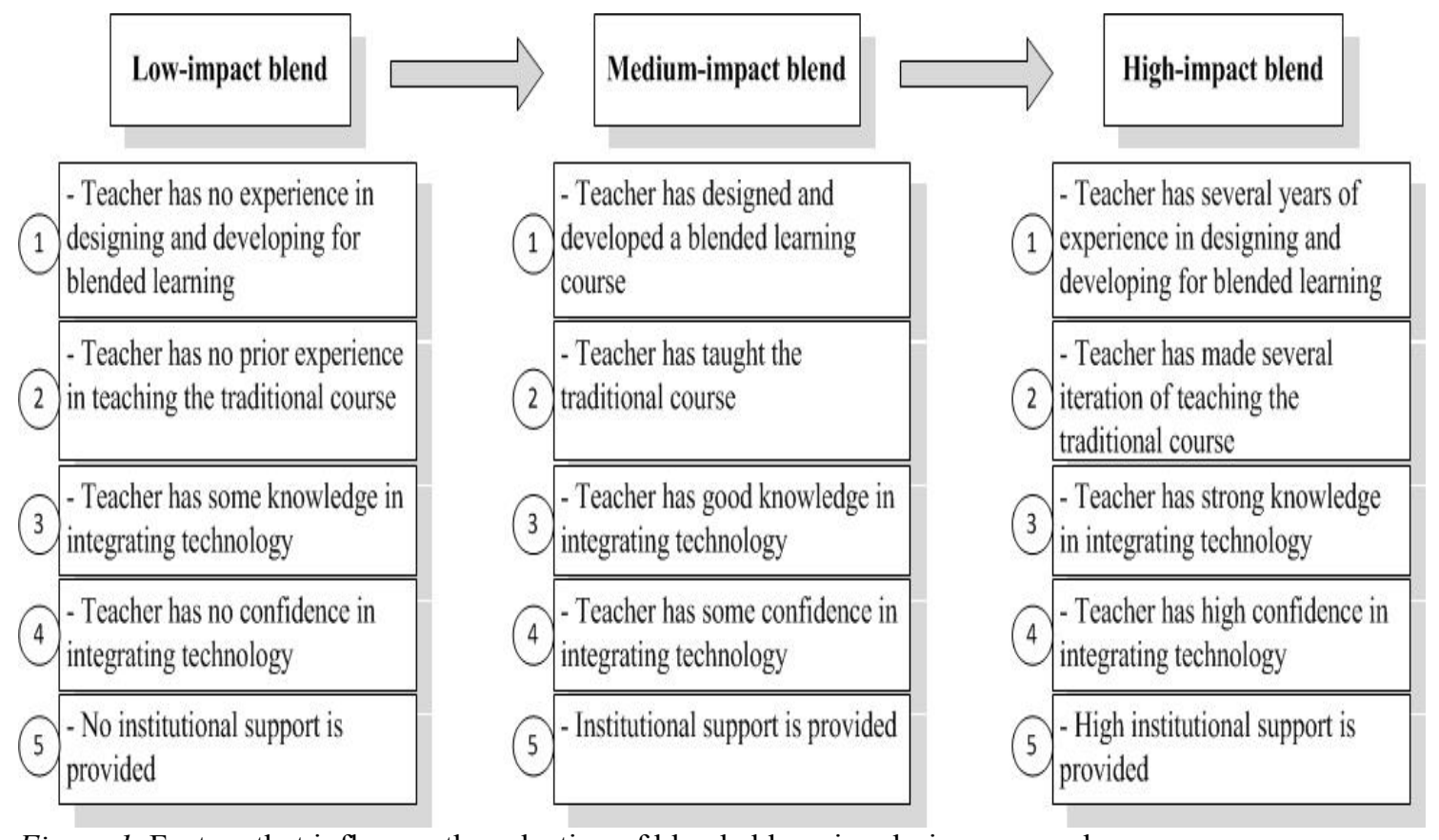

Figure 1. Factors that influence the selection of blended learning design approaches

\section{Discussion}

By examining the different ways of designing blended learning courses, three distinct approaches were identified (see Figure 2): low-impact blend (adding extra activities to an existing course), medium-impact blend (replacing activities in an existing course) and high-impact blend (building the blended course from scratch). Classifying these approaches as low, medium or high impact blends has been done according to the potential changes to the existing teaching program and student learning experience. Moving from the low to a higher impact approach requires from the instructor increasing effort, technological knowledge, confidence, support, skill and expertise; however, there is also increasing potential for the traditional course to be improved. 
The low-impact blend is the design approach that requires the least time and effort, and is the safest in terms of risk of failure. Driven by a specific pedagogical need, an instructor can directly add a new activity to his/her course with minimal rethinking and replanning of the course. As an add-on to the course, no reworking of the course is usually required; however, successful application of this approach may require some technical knowledge. The instructor will need to investigate possible blended learning components, evaluate these in terms of the pedagogical goals of the course, implement the selected component and help students use during the learning process. The risk of the new blended course failing is low, as the traditional teaching modes of lectures and tutorials will remain almost the same and the learning objectives of the course can be covered regardless as to whether or not the new activity is used. The teacher can stay in his/her comfort zone: the additional activities are introduced for the benefit of the student, without the teacher having to change his/her teaching style.

The potential enhancement that low-impact blend can bring to an existing teaching program and to the student learning experience is minimal, as only a small number of blended activities can be introduced to a traditional course without the course being perceived by students as being overloaded. Adding components to the extent of overloading may then involve replacement of existing components and would be, in effect, a medium-impact blended approach.

Moving to a medium-impact blend, the application of the approach becomes more complex. Building a successful blend using this approach is not just about finding a new online component that can be added to the course to enhance students' experiences, as in the low-impact blend. A deeper look at the course objectives is needed to identify all parts of the course that could be better presented in an online format, and then an examination of available educational technologies is needed to select those that best meet the students' needs. Reaching a harmonious balance between online and face-to-face components may take a number of iterations of the course. Long-term planning for a continuous process of introduction and evaluation of new components may be needed.

Experience in teaching the traditional course in addition to experience in designing for blended learning are two critical success factors for teachers using a medium-impact blended design approach. Experience in teaching the traditional course can help teachers decide what parts of the course need to be replaced or what parts can be better delivered in online format. Experience in designing for blended learning may result in teachers having confidence in using technology, knowledge about what educational technologies can better meet their students' needs and understanding of how to develop a good plan for the replacement process. Risk of failure is higher than the low-impact approach, as through the replacement of course components teachers commit to changing their teaching style, and there is no going back to old methods.

Institutional support in the form of professional development, technical assistance and workload relief is important for the success of this approach. Educational institutions also need to provide continuing professional development to help teachers in learning new teaching and technology skills and in deciding the most appropriate delivery methods to achieve their course objectives. Educational designers should also be there to provide advice about the range of available technologies and the advantages and disadvantages of using each one of them.

The pedagogical benefits achieved through a medium-impact approach are potentially higher than the low-impact approach because more changes are possible to the existing teaching program and a deeper look at course objectives with learners' needs in mind is necessary to select the most appropriate blended components. The intention is to improve student learning experience through choice of activities more appropriate to their needs and circumstances.

Building a course from scratch using a high-impact blend design approach is the most difficult to apply. It requires teachers to invest a great amount of time and effort in course design. Some studies suggest that six months to one year lead time for course development is needed. As Harriman (2004) and Hofmann (2006) maintain, teachers would need to look at each single learning outcome of the course with blended learning and learners' needs in mind. For each outcome, they would need to develop a full understanding that can help them to determine the best delivery option for that outcome. They would also need to consider and fully understand a large number of possible blended learning components that can be used to 
deliver that outcome. In some cases they would find it better to deliver that outcome face-to-face; in other cases online delivery can be better. In most other cases, combinations of face-to-face and online deliveries are more appropriate.

The risk of failure of this approach is higher than with the lower impact approaches. Building a new course is a large investment in time and resources. A totally new and untried course might be introduced to the students, and the teacher has to step out of his/her comfort zone and commit to the new approach.

Several years of experience in designing for blended learning in addition to several iterations of teaching the traditional course is important to successfully apply this approach. Teachers need to have a full understanding of students' needs and be familiar with a variety of tools that can be used to better achieve the course objectives. They also need to be confident in using computer technology in an educational context. In many cases using a high-impact blend approach may only be possible with institutional support in the form of time release, technical support, funding and professional development. Professional development should focus on introducing new technologies that teachers have not previously used in their courses. To minimize the risk of failure, educational designers should participate in the design process by providing advice about the most appropriate online components and by reviewing the course after it has been developed.

When the high-impact blend design approach is properly applied, the maximum benefits of blended learning can be obtained. Starting from a fresh perspective provides a better chance to produce a successful course which maximises the benefits of the traditional and online teaching modes. It enables teachers to try a wide range of new blended components (see Figure 2) and to better integrate them in the course. Teachers will also have the opportunity to reconsider the most appropriate delivery method for each course objective according to their students' needs. There is a high potential for large changes in the existing teaching program and hopefully large improvements to student learning experience through a teaching program more tailored to their needs and circumstances.

Selecting a blended learning design approach should not be made without considering a number of important factors (see Figure 1). Teachers new to blended learning are advised to start with the lowimpact blend. After gaining more knowledge, confidence and experience, they should move to the medium-impact approach. When applying the medium-impact blend, they could set a replacement plan for a couple of semesters to familiarize themselves with more technology and to know their courses better, and after that they could consider the high-impact blend.

\section{Conclusion}

The term blended learning has no single agreed upon definition. Although this might appear to be an academic point, the consequence is that it allows teachers and course designers to develop their own understandings of the term within the context of their courses or institutions, and then use that as basis to design their blended courses. This paper identified three distinct approaches for designing blended courses (low-impact blend, medium-impact blend and high-impact blend) that emerged as result of the multitude of definitions of blended learning. This classification has been made according to the potential changes to the existing teaching program and student learning experience. The main advice is that teachers with no experience in designing for blended learning should start with the low-impact approach, and when they gain more experience they can move to the medium-impact, and only when they have enough confidence, knowledge and experience in blended learning design, they can try the high-impact approach. 


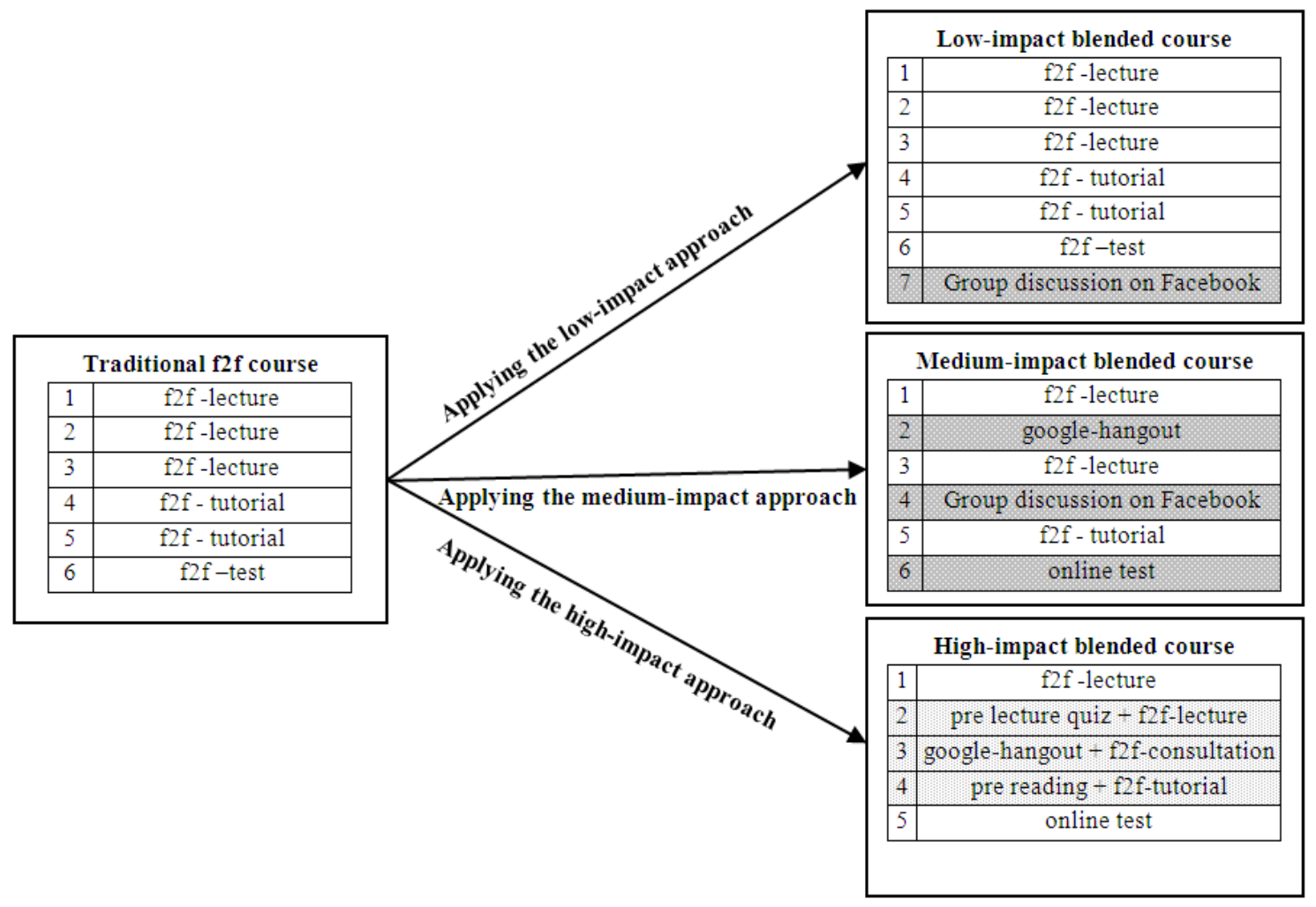

Figure 2. Applying the three different approaches to a traditional face-to-face course

The ultimate goal should be reconsideration of the whole course objectives with learners' needs in mind. This goal can be more readily achieved by building the whole course from scratch. Such an approach can allow teachers to start from a fresh perspective, rethinking the whole course and possible delivery mediums to integrate into their courses primarily with learners' needs in mind. However, going straight to the high-impact blend is risky and can result in an unsuccessful course. The large choice of delivery mediums, wide variety of technology combinations and the lack of successful models to follow means that novice blended learning teachers will face very complex situations and therefore pressure when fully redesigning their courses. Familiarity with technology and incremental experimentation with blended learning can help teachers to gain more confidence and understanding about how technological media can be integrated in the traditional face-to-face experience to better meet their students' needs. The goal can also be achieved by applying the medium-impact blend; however, that can take a long time. When developing their long-term redesign plan, teachers can plan it in a way that allows them in the long term to cover all course components and check if each particular component should be replaced by an online one, or can be better delivered in the traditional face-to-face format.

\section{References}

Amiel, T., \& Orey, M. (2006). Do you have the time? Investigating online classroom workload. Journal of Educational Technology Systems, 35, 31-43.

Aycock, A., Garnham, C., \& Kaleta, R. (2002). Lessons learned from the hybrid course project. Teaching with Technology Today, 8(6), 9-21. Retrieved from http://www.uwsa.edu/ttt/articles/garnham2.htm

Biggs, J. (1996). Enhancing teaching through constructive alignment. Higher Education, 32, 347-364. doi:10.1007/BF00138871

Bliuc, A.-M., Goodyear, P., \& Ellis, R. A. (2007). Research focus and methodological choices in studies into students' experiences of blended learning in higher education. The Internet and Higher Education, 10, 231-244. doi:10.1016/j.iheduc.2007.08.001

Boyle, T., Bradley, C., Chalk, P., Jones, R., \& Pickard, P. (2003). Using blended learning to improve student success rates in learning to program. Journal of Educational Media, 28, 165-178. 
Brunner, D. L. (2006). The potential of the hybrid course vis-à-vis online and traditional courses. Teaching Theology \& Religion, 9, 229-235. doi:10.1111/j.1467-9647.2006.00288.x

Carman, J. M. (2002). Blended learning design: Five key ingredients. Retrieved from http://www.agilantlearning.com/pdf/Blended\%20Learning\%20Design.pdf

Cennamo, K. S., Ross, J. D., \& Ertmer, P. A. (2009). Technology integration for meaningful classroom use: A standards-based approach. Belmont, California: Wadsworth.

Chen, W., \& Looi, C. (2007). Incorporating online discussion in face to face classroom learning: A new blended learning approach. Australasian Journal of Educational Technology, 23, 307-326. http://ascilite.org.au/ajet/submission/index.php/AJET/index

Clark, D. (2003). Blended learning: An epic white paper. Retrieved from http://www.oktopusz.hu/domain9/files/modules/module15/261489EC2324A25.pdf

Cook, K., Owston, R., \& Garrison, D. R. (2004). Blended learning practices at COHERE universities. Retrieved from http://www.yorku.ca/irlt/reports/BLtechnicalreportfinal.pdf

Deperlioglu, O., \& Kose, U. (2013). The effectiveness and experiences of blended learning approaches to computer programming education. Computer Applications in Engineering Education, 21, 328-342. doi:10.1002/cae.20476

Dönmez, O., \& Aşkar, P. (2005, June). A blended learning environment for a course on educational software in the framewok of project management. Paper presented at the the IADIS International Conference e-society 2005, Malta. Retrieved from https://www.academia.edu/attachments/30166694/download_file?s=regpath

Driscoll, M. (2002). Blended learning: Let's get beyond the hype. Retrieved from http://www07.ibm.com/services/pdf/blended_learning.pdf

Duhaney, D. C. (2004). Blended learning in education,training, and development. Performance Improvement, 43(8), 35-38. doi:10.1002/pfi.4140430810

Dziuban, C., Moskal, P., \& Hartman, J. (2005). Higher education, blended learning, and the generations: Knowledge is power: No more. Elements of quality online education: Engaging communities. Needham, MA: Sloan Center for Online Education. Retrieved from http://inspvirtual.mx/espm30/docentes/formdocente/jd2013/Julio_tlalpan/material_apoyo/blendedlear ning.pdf

Ellis, R. A., Steed, A. F., \& Applebee, A. C. (2006). Teacher conceptions of blended learning, blended teaching and associations with approaches to design. Australasian Journal of Educational Technology, 22, 312-335 http://ascilite.org.au/ajet/submission/index.php/AJET/index

Ertmer, P. A, \& Ottenbreit-Leftwich, A. T. (2010). Teacher technology change: How knowledge, confidence, beliefs, and culture intersect. Journal of Research on Technology in Education, 42, 255 284. doi:10.1080/15391523.2010.10782551

Garrison, D. R., \& Kanuka, H. (2004). Blended learning: Uncovering its transformative potential in higher education. The Internet and Higher Education, 7, 95-105. doi: 10.1016/j.iheduc.2004.02.001

Garrison, D. R., \& Vaughan, N. D. (2011). Blended learning in higher education: Framework, principles, and guidelines. San Francisco: John Wiley \& Sons.

Graham, C. R. (2009). Blended learning models. Encyclopedia of Information Science and Technology, 375-382. Hershey, PA: IGI Global.

Graham, C. R. (2012a). Blended learning systems: Definition, current trends, and future directions. In C. J. Bonk \& C. R. Graham (Eds.), Handbook of blended learning: Global perspectives, local designs (pp. 3-21). San Francisco, CA: John Wiley \& Sons.

Graham, C. R. (2012b). Emerging practice and research in blended learning. M.J. Moore (Ed.), Handbook of distance education (pp. 333-350). New York, NY: Routledge.

Harriman, G. (2004). Blended learning. Retrieved from http://www.grayharriman.com/blended_learning.htm\#1

Hofmann, J. (2006). Why blended learning hasn't (yet) fulfilled its promises. In C. J. Bonk \& C. R. Graham (Eds.), Handbook of blended learning: Global perspectives, local designs (pp. 27-40). San Francisco, CA: Pfeiffer Publishing.

Hoic-Bozic, N., Mornar, V., \& Boticki, I. (2009). A blended learning approach to course design and implementation. Education, IEEE Transactions on, 52, 19-30.doi:10.1109/TE.2007.914945

Huang, R., \& Zhou, Y. (2005). Designing blended learning focused on knowledge category and learning activities. In C. J. Bonk \& C. R. Graham (Eds.), Handbook of blended learning: Global perspectives, local designs (pp. 296-310). San Francisco, CA: Pfeiffer Publishing. 
Kaleta, R., Garnham, C., \& Aycock, A. (2005). Hybrid courses: Obstacles and solutions for faculty and students. Retrieved from http://www.uwex.edu/disted/conference/Resource_library/proceedings/03_72.pdf

Kaleta, R., Skibba, K., \& Joosten, T. (2007). Discovering, designing, and delivering hybrid courses. In A. G. Picciano \& C. D. Dziuban (Eds.), Blended learning research perspectives (pp. 111-143). Needham, MA: Sloan-C.

Lee, G., Fong, W. W., \& Gordon, J. (2013). Blended learning: The view is different from student, teacher, or institution perspective. Hybrid Learning and Continuing Education (pp. 356-363). Berlin, Heidelberg: Springer.

Lee, S., \& Lee, H. (2008, November). Professors' perceptions and needs on blended e-learning. Paper presented at the World Conference on E-Learning in Corporate, Government, Healthcare, and Higher Education 2008, Las Vegas, Nevada, USA. Retrieved from http://www.editlib.org/p/29737

Littlejohn, A., \& Pegler, C. (2007). Preparing for blended e-learning. Abingdon, Oxon: Taylor \& Francis.

McCarthy, J. (2010). Blended learning environments: Using social networking sites to enhance the first year experience. Australasian Journal of Educational Technology, 26, 729-740. http://ascilite.org.au/ajet/submission/index.php/AJET/index

Means, B., Toyama, Y., Murphy, R., Bakia, M., \& Jones, K. (2009). Evaluation of evidence-based practices in online learning: A meta-analysis and review of online learning studies. Washington, DC: U.S. Department of Education.

Mortera-Gutiérrez, F. (2006). Faculty best practices using blended learning in e-learning and face-to-face instruction. International Journal on E-learning, 5, 313-337. http://www.editlib.org/j/IJEL/

Moskal, P., Dziuban, C., \& Hartman, J. (2013). Blended learning: A dangerous idea? The Internet and Higher Education, 18, 15-23. doi:10.1016/j.iheduc.2012.12.001

Newcombe, E. (2011, June). A work in progress: Refining the "blend" of face-to-face and online instruction. Paper presented at the World Conference on Educational Multimedia, Hypermedia and Telecommunications 2011, Lisbon, Portugal. Retrieved from http://www.editlib.org/p/38304

Norberg, A., Dziuban, C. D, \& Moskal, P. D. (2011). A time-based blended learning model. On the Horizon, 19, 207-216. http://www.emeraldinsight.com/loi/oth

Ocak, M. A. (2011). Why are faculty members not teaching blended courses? Insights from faculty members. Computers \& Education, 56, 689-699.

Oliver, M., \& Trigwell, K. (2005). Can 'blended learning' be redeemed? E-learning and Digital Media, 2, 17-26.

Osguthorpe, R. T., \& Graham, C. R. (2003). Blended learning environments: Definitions and directions. Quarterly Review of Distance Education, 4, 227-233.

Partridge, H., Ponting, D., \& McCay, M. (2011). Good practice report: Blended learning. Sydney, NSW: the Australian Learning and Teaching Council.Retrieved from http://eprints.qut.edu.au/47566/1/47566.pdf

Picciano, A. G. (2009). Blending With Purpose: The Multimodal Model. Journal of the Research Center for Educational Technology (RCET), 5(1), 4-14.

Ragan, L. (2007). Teaching blended learning courses. Retrieved from http://cnx.org/content/m15048/latest/?collection=col10453/latest

Reeves, T. C. (2003). Storm clouds on the digital education horizon. Journal of Computing, 15(1), 3-26. http://www.editlib.org/j/ISSN-1042-1726/

Ross, B., \& Gage, K. (2006). Global perspectives on blending learning: Insight from WebCT and our customers in higher education. In C. J. Bonk \& C. R. Graham (Eds.), Handbook of blended learning: Global perspectives, local designs (pp. 155- 168). San Francisco, CA: Pfeiffer Publishing.

Sharma, P. (2010). Blended learning. ELT Journal, 64, 456-458.http://eltj.oxfordjournals.org/

Sharpe, R., Benfield, G., Roberts, G., \& Francis, R. (2006). The undergraduate experience of blended elearning: A review of UK literature and practice. Retrieved from http://business.heacademy.ac.uk/assets/documents/research/literature reviews/blended elearning full review.pdf

Silverwood, T. (2006). Blended Learning Made Easy. http://www.chs.nihonu.ac.jp/institute/human/kiyou/74/10.pdf

Stacey, E., \& Gerbic, P. (2008). Success factors for blended learning. In Hello! Where are you in the landscape of educational technology? Proceedings ascilite Melbourne 2008. http://www.ascilite.org.au/conferences/melbourne08/procs/stacey.pdf 
Torrisi-Steele, G., \& Davis, G. (2000). “A website for my subject”: The experiences of some academics' engagement with educational designers in a team based approach to developing online learning materials. Australian Journal of Educational Technology, 16, 283-301. http://www.ascilite.org.au/ajet/submission/index.php/AJET/index

Twigg, C. A. (2003). Improving learning and reducing costs: New models for online learning. EDUCAUSE Review 38(5), 28-38.http://www.educause.edu/ero

Vaughan, N. (2007). Perspectives on blended learning in higher education. International Journal on ELearning (IJEL), 6, 81. http://www.editlib.org/j/IJEL/

Verkroost, M. J., Meijerink, L., Lintsen, H., \& Veen, W. (2008). Finding a balance in dimensions of blended learning. International Journal on E-Learning (IJEL), 7, 499522.http://www.editlib.org/j/IJEL/

Walters, B. (2008, August 12). Blended learning-classroom with on-line. The CALSCA Online Magazine. Retrieved from http://calsca.com/Writings/walters_blended_learning.htm

Westbrook, K. (2008). The beginning of the end for blended learning? IATEFL CALL Review 2008. Retrieved from http://www.psa.eu.com/wp-content/uploads/2011/06/DeathOfBlendedLearning.pdf

Wozney, L., Venkatesh, V., \& Abrami, Pp. (2006). Implementing computer technologies: Teachers' perceptions and practices. Journal of Technology and Teacher Education, 14, 173-207. http://www.editlib.org/j/JTATE/

Corresponding author: Ali Alammary, ali.alammary@monash.edu

Australasian Journal of Educational Technology (C) 2014.

Please cite as: Alammary, A., Sheard, J., \& Carbone, A. (2014). Blended learning in higher education: Three different design approaches. Australasian Journal of Educational Technology, 30(4), 440-454. 